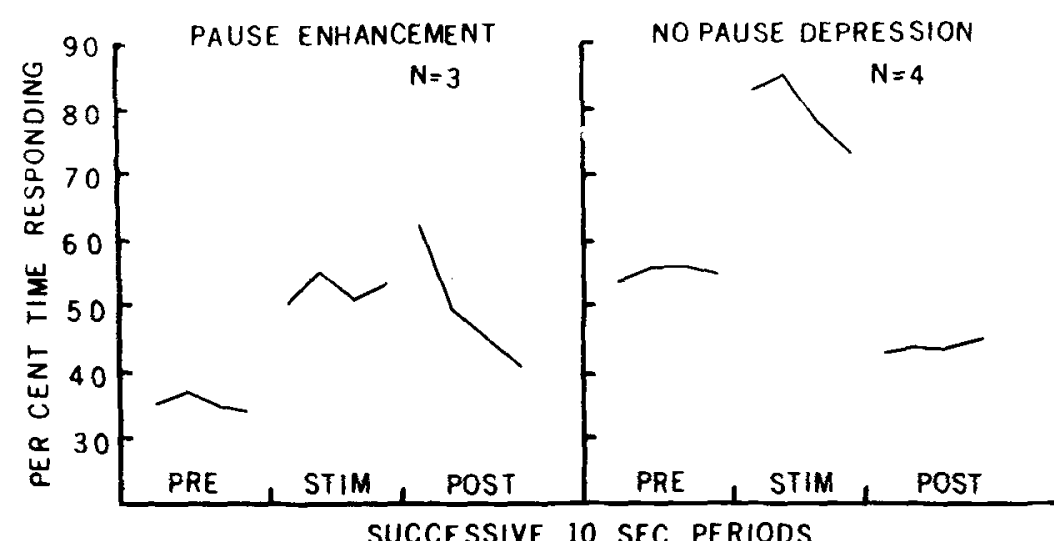

Fig. 2. Mean per cent time responding for each group before, during, and after stimulation.

\section{REFERENCES}

CARDER, B. Lateral hypothalamic stimulation and avoidance in rats. Journal of Comparative \& Physiological Psychology, 1969, in press.

MARGULES, D. L., \& STEIN, L. Facilitation of Sidman avoidance by positive brain stimulation. Journal of Comparative \& Physiological Psychology, 1968, 66, 182-184.

OLDS, J., \& OLDS, M. E. The mechanism of voluntary behavior. In R. G. Heath (Ed.), The role of pleasure in behavior. New York: Hoeber, 1964. Pp. 23-53.

STEIN, L. Reciprocal action of reward and punishment mechanisms. In R. G. Heath (Ed.), The role of pleasure in behavior. New York: Hoeber, 1964. Pp. 113-139.

TROWILL, J. A., PANKSEPP, J,, \& GANDLEMAN, R. An incentive model of rewarding brain stimulation. Psychological Review, 1969, 76, 264-281.

WILLIAMS, D. R. Negative induction in behavior reinforced by central stimulation. Psychonomic Science, 1965, 2, 341-342.

\section{NOTES}

1. This research was supported by Grant GB-2475 from the National Science Foundation to David R. Williams, while the author was a PHS predoctoral fellow.

2. Present address: Department of Psychology, University of California, Los Angeles, Calif. 20024.

3. Williams, D. R., \& Carder, B. Interaction of rewarding and aversive brain stimulation. Manuscript in preparation.

\title{
Variations in secondary reinforcers as a function of temporal relationship to UCS and UCS intensity
}

\section{BARRY MACKAY and HEATHER $B R A D Y$, Memorial University of Newfoundland, St. John's, Newfoundland, Canada}

Two predictions were tested: (1) that stimuli paired with shock termination become positive reinforcers, and (2) that the attractiveness of the reinforcer will be proportional to the aversiveness of shock preceding it. Two experiments carried out various tone-shock pairings; speed in a runway was subsequently observed when the tone was presented as a reward. Both predictions were confirmed.

Mowrer's behavior theory (1961) suggests that stimuli preceding aversive stimulation acquire negative reinforcing properties, while stimuli paired with the termination of such aversive stimulation become positive reinforcers through their contiguity with drive reduction. Mowrer \& Aiken (1954) have shown that stimuli preceding shock are effective negative reinforcers, but they did not conclusively demonstrate that stimuli paired with shock termination were positive reinforcers. Goodson (1954), Smith \& Buchanan (1954), and Murray \& Strandberg (1965) have been able to demonstrate under several conditions that stimuli contiguous with shock offset are positive reinforcers.

It is claimed by Mowrer that the stimuli paired with the termination of noxious stimulation develop into positive reinforcers through their contiguity with "relief" resulting from the termination of discomfort or drive. This position implies that the amount of relief (and hence the attractiveness of stimuli paired with the relief) is proportional to the intensity of aversive stimulation preceding the relief. Variations in the length or intensity of the UCS should produce differences in the reinforcing effectiveness of stimuli paired with the termination of aversive stimulation. Murray \& Strandberg (1965) observed no relationship between shock length and the reinforcing properties of the stimulus paired with the termination of the shock; however, length of shock was not controlled and was allowed to vary between Ss.

The purpose of this study was to confirm the previous findings that stimuli paired with shock termination become positive reinforcers. The second and major purpose of the study was to test an associated hypothesis that the attractiveness of stimuli accompanying UCS termination is proportional to the aversiveness of the UCS. Both hypotheses were tested by the pairing of a tone with shock termination and subsequently observing the effect of the tone as a reward on speed of running in a runway.

\section{EXPERIMENT 1 \\ Subjects}

Fifty male albino rats, 90-130 days old, were assigned randomly to five groups. All Ss were housed in pairs, with unlimited access to food and water except during training sessions.

\section{Apparatus}

Shock-tone conditioning was carried out in a sound-deadened ventilated compartment (Grason-Stadler E3125AA). Shock was administered through the grid floor by means of a shock-generator scrambler (Grason-Stadler E1064GS, set at $0.6 \mathrm{~mA}$ for all groups). The tone was presented in the chamber at $-20 \mathrm{~dB}$ according to a General Radio sound-level meter. Performance in the $3 \mathrm{ft} \times 4$ in. $x 4$ in. Hunter runway was measured by timers controlled by photocells placed 3 in. outside the start and goal boxes. Handling of each $S$ between trials was eliminated by exchanging start and goal boxes at the completion of each trial. The sides of the runway were covered with black cardboard and the top was covered with glass.

\section{Procedure}

Group 1: Twenty Ss received 20 shocks of $3-\mathrm{sec}$ duration, spaced at intervals ranging randomly from $40-80 \mathrm{sec}$ at an average of $60 \mathrm{sec}$ A $1,000 \cdot \mathrm{Hz}$ tone overlapped the termination of each UCS for $0.5 \mathrm{sec}$ and continued for $2.5 \mathrm{sec}$ after the termination of the UCS. After $10 \mathrm{~min}$ rest, each $S$ was then placed in the runway start box. Half of the Ss received the CS as reward upon reaching the goal (Group 1A). The remaining $S$ did not receive any tone in the goal (Group IB). This procedure was 
repeated for 15 trials or until an $\mathrm{S}$ was withdrawn after three consecutive runs of over $180 \mathrm{sec}$ each.

Group 2: Ten Ss received the UCS unaccompanied by the CS delivered at the same intervals as in Group 1. All other procedures were identical to those of Group 1A.

Group 3: Ten Ss received the CS only, delivered at the same intervals as in Group 1. All other procedures were identical to those of Group $1 \mathrm{~A}$.

Group 4: Ten Ss received 20 quasi-random pairings of the tone and shock. The tone was presented randomly throughout the interval between shocks, but the randomness was controlled so that the tone was never coincident with the UCS.

\section{EXPERIMENT 2}

Subjects

Forty male albino rats, 90-130 days old, were assigned randomly to four groups and maintained on a 23 -h water-deprivation schedule. Food was available ad lib.

\section{Apparatus}

The apparatus was identical to that used in Experiment 1 except that a runway, $8 \mathrm{ft} \times 4$ in. $\times 12$ in. high, constructed of corrugated cardboard, was used.

\section{Procedure}

Each $S$ was trained over 10 trials to run for a 3-drop water reward in the runway goal box. After a 5-min rest, each $\mathrm{S}$ received the shock-tone conditioning.

Group 1: Using the same shock-tone intervals as in Experiment 1, Ss received 20 pairings of $0.1-\mathrm{mA}$ shock and tone.

Group 2: Procedure was identical to Group 1 except that $0.6-\mathrm{mA}$ shock was given.

Group 3. Identical to Group 1 except that the $S$ s received 1.0-mA shock.

Group 4: Identical to Group 1 except that the Ss received quasi-random sequences of 1.0-mA shock and tone.

After a 10-min rest, each $S$ was returned to the runway start box and given 15 extinction trials. The $3 \cdot \mathrm{sec}$ tone was presented when $S$ reached the goal box with the empty water container.

\section{RESULTS}

For Experiment 1, all time scores were converted to their reciprocals for analysis with Duncan's Multiple Range Test (Edwards, 1962). Analysis revealed significant differences only when start-box latency and alley speed measures were combined. The differences in speed for the five groups is shown in Fig. 1. Group 1A (tone at shock offset, tone in goal) showed significantly greater running speed than any of the control conditions during the last block of three trials $(p<.05)$. There were no significant differences in running speed between any of the groups during

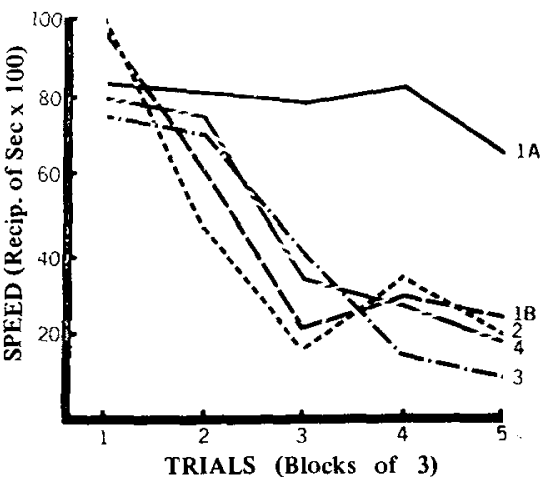

Fig. 1. Mean runway speed as a function of extinction trials for the five treatment groups used in Experiment 1.

the first block of three trials. None of the control groups was significantly different from each other during the last block of trials.

For Experiment 2, the reciprocal of time scores was again used for analysis. No differences in speed were found to be significant during the initial training period or immediately after shock-tone conditioning. The differences in running speed during the 15 extinction trials are shown in Fig. 2. According to Duncan's test, all four groups were significantly different from each other during the last block of three trials $(p<.05)$, with Group 3 showing the greatest resistance to extinction.

\section{DISCUSSION}

Experiment 1 confirms the proposal that a stimulus paired with shock termination becomes a positive rather than a negative secondary reinforcer. This conclusion is supported by the performance of Group $1 \mathrm{~A}$ in the runway relative to all other conditions. Group 1A, reinforced in the runway by a tone previously associated with shock termination, showed least decrement in runway speed. The possible

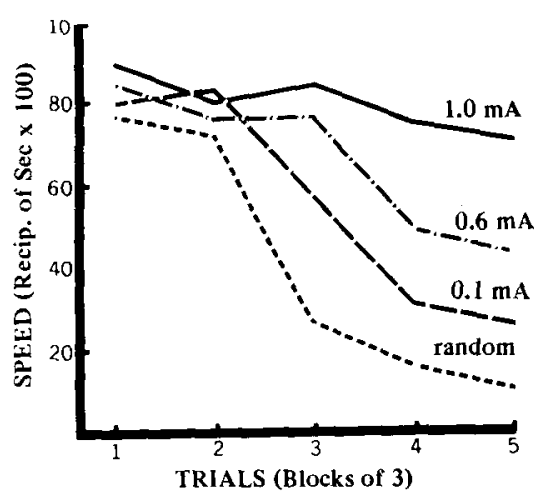

Fig. 2. Mean runway speed as a function of extinction trials for the four treatment conditions used in Experiment 2. reinforcing effects produced by stimulus change through the appearance of a tone in a novel environment can be discounted in view of the evidence from Group 2 in which a novel tone was presented in a novel environment. It would be reasonable to assume that if stimulus change or novelty was a valid explanation, Group 2 should show speeds comparable to those of Group IA.

The results of Experiment 2 appear to indicate that the effectiveness of this secondary reinforcer is a monotonic function of the aversiveness of the stimulation with which it is associated.

Both studies showed that Ss exhibited no differences in speed during initial extinction in the runway, but speed differences did appear as training continued. This result indicates that the various conditioning procedures did not produce variations in motivational or arousal states that would be expected to produce initial speed differences as a result of prior exposure to shock. The differences appear to be solely a function of the reinforcing effectiveness of the tone offered in the goal box.

Among those studies that failed to support the results reported above were Littman \& Wade (1955) and Nefzger (1955). These failures might be accounted for in terms of the differences in shock procedures. Specifically, Littman and Wade used a $0.5-\mathrm{sec}$ shock in a confinement tube (where confinement could act as an effective stressor), and Nefzger used escapable shock in a $T$-maze; shock length was not controlled for each $\mathrm{S}$.

\section{REFERENCES}

EDWARDS, A. L. Experimental design in psychological research. (rev. ed.) New York: Holt, Rinehart \& Winston, 1962.

GOODSON, F. E. Secondary reinforcing and motivating properties of stimuli contiguous with shock termination. Unpublished doctoral dissertation, University of Missouri, 1954.

LITTMAN, R. A., \& WADE, E. A. A negative test of the drive-reduction hypothesis. Quarterly Journal of Experimental Psychology, 1955, 18, 56-66.

MOWRER, O. H. Learning theory and behovior. New York: Wiley, 1961.

MOWRER, O. H., \& AIKEN, E. G. Contiguity vs. drive-reduction in conditioned fear; temporal variations in conditioned and unconditioned stimulus. American Journal of Psychology, $1954,67,26-38$

MURRAY, A. K., \& STRANDBERG, J. M. Development of a conditioned positive reinforcer through removal of an aversive stimulus. Journal of Comparative \& Physiological Psychology, 1965, 60, 281-283.

NEFZGER, M. D. Exploratory studies of the secondary reinforcing properties of stimuli associated with shock reduction. Unpublished doctoral dissertation, State University of Iowa, 1955.

SMITH, M. P., \& BUCHANAN, G. Acquisition of secondary reward by cues associated with shock reduction. Journal of Experimental Psychology, 1954, 48, 123-126. 